\title{
SOBRE ACADÉMICOS, ACADEMIA Y UNIVERSIDAD. NECESIDAD DE UNA CLARIFICACIÓN
}

\section{Escuela, universidad, academia}

Las tres instituciones más perdurables en la cultura occidental se relacionan con la intermediación frente a lo divino, con la defensa del espacio y las personas, y con la preparación de las nuevas generaciones. Por ello, la Iglesia, el Ejército y la Universidad se encuentran en el occidente medieval europeo en forma notable e ininterrumpida.

En tanto nociones genéricas de ordenamiento social, estas instituciones adoptan diversas formas según el contexto y la tradición. "Iglesia" alude no solamente a las instituciones derivadas de la fe cristiana sino a toda forma de intermediación con lo divino y de regimentación de la vida moral basada en creencias en lo trascendente. "Ejército" se refiere a las formas institucionales o irregulares de defensa del territorio, las naciones o las creencias. "Universidad" es concepto genérico que significa agrupación de sabios y talentos que enseñan y aprenden en comunidad.

Los intelectuales alemanes que debatieron la fundación de la nueva universidad, concretada en Berlín en 1810, culminando el perfeccionamiento del Estado prusiano, fueron unánimes en distinguir tres variedades de instituciones relacionadas con el saber: la escuela, la universidad y la academia (Fichte, Schleiermacher, Humboldt, Instituto de Filosofía, Universidad de Montevideo, 1958).

La primera debía preparar los talentos, inspirando en ellos el afán por saber y entregando aquellos conocimientos que la sociedad disputare por esenciales y unánimemente aceptados. La academia, por su parte, debía concentrarse en el acrecentamiento del saber en áreas 
de alta especialización. Entre ambas, la universidad debía cultivar el intelecto mediante el arte de su empleo adecuado. Obsérvese que esta concepción de universidad difiere de la medieval, derivada del estudio de los textos canónicos y sagrados, y difiere asimismo de la escuela técnica superior, orientada a preparar buenos trabajadores para el Estado. Esta universidad, que antes de fundarse en Berlín concitó opiniones de Fichte, Schleiermacher y, ciertamente, Wilhelm von Humboldt, debía prevalecer sobre otras instituciones por su adecuado balance entre investigación y enseñanza (Forschung und Lehre). Distinguiendo entre educación, investigación y enseñanza, lo que Humboldt vino finalmente a defender fue la unión de ambas, haciendo de esta nueva institución decimonónica una mezcla de escuela superior y de academia.

Otros intelectuales que examinaron esta cuestión luego de la etapa fundacional abogaron por mantener las funciones de investigar y pensar en la institución académica, mientras relegaron la educación y la enseñanza a escuelas superiores y universidades. Todavía en países europeos, particularmente en los de la órbita socialista, la función investigadora recayó en las academias de ciencias, en tanto la enseñanza superior se concentró en las universidades.

En el caso de Chile, la universidad republicana, heredera de la universidad clerical (Santo Tomás) y de la universidad real (San Felipe), fue al comienzo una asociación de gentes de letras, al estilo de una academia a la que se ingresaba tras elección y disertación. Luego, hacia 1879, adquirió su carácter docente y, finalmente, en el siglo XX, su orientación hacia la investigación científica (Mellafe et al., 1992; Serrano, 1993). Fusionando estos tres aspectos, el académico, el docente y el investigador, esta institución, como otras de su tipo, abriga en su seno intereses diversos y en ocasiones contradictorios (Lolas, 2004). Así, por ejemplo, el investigador que desea progresar en su carrera científica puede considerar que las obligaciones docentes distraen su tiempo y limitan su creatividad. A la inversa, el maestro puede considerar que la creación de conocimientos originales debe ceder en importancia a la fidedigna transmisión y cultivo de la 
erudición y del saber. Como es bien sabido, la erudición dejó de ser la marca de la ciencia, al menos en sus versiones contemporáneas, y fue reemplazada, como señala Heidegger, por un proceso social llamado "investigación" (Heidegger, 1958). Esto significa, en esencia, reemplazar el saber como objeto estático, como colección o tesoro, por el saber en tanto movimiento, búsqueda, proceso. La ciencia, en tanto profesión, impone demandas y supone privilegios y obligaciones no siempre cabalmente reflejados en la institución universitaria. Súmese a ello la inevitable participación en los procesos de conducción, administración y planificación y se tiene un cuadro de lo complejo que significa pertenecer a una institución multifacética y multiforme.

Este trabajo propone destacar la dificultad inherente a tipificar, evaluar y desarrollar la tarea universitaria en entornos diversos, destacando la multiplicidad de papeles sociales que deben adoptar sus miembros y sus profesionales.

\section{La heterogeneidad de papeles sociales en la universidad}

No cabe duda de que la complejidad de una institución se relaciona con la complejidad de los papeles sociales que obliga a sus miembros a adoptar. De esta forma, el empleado de una universidad puede ser en ocasiones investigador, en otras profesor y, aún en otras, administrador de bienes y servicios. Tal complejidad no guarda necesaria relación con el tamaño de la institución ni con los capitales que transa en mercados. Se vincula con sus metas, misiones y autopercepción. De este modo, la definición de universidad interpela un conjunto de polisemias, de significados múltiples, que a veces coexisten en una misma institución y obligan, por consiguiente, a una "tensión de rol" que puede ser muy notable. No debe olvidarse que los científicos, como grupo profesional, obedecen a un ethos distinto del de los administradores, los profesionales liberales o los maestros. Por ello, el médico que labora en la universidad tiene lealtades con su grupo de pertenencia profesional, con sus creencias en materia moral y religiosa y con su condición de empleado de una organización, sea ésta pública 
o privada. De estas tensiones, fácilmente ejemplificables en casos de conflictos laborales o, más cotidianamente, en la distribución de la atención y el tiempo, surgen dilemas de difícil resolución. Tal vez la consecuencia más importante de esta circunstancia dilemática sea la identidad borrosa o difusa que confiere y la consiguiente ausencia de una apreciación pública uniforme. Esto incide, a su vez, en la valoración social del papel del universitario en tanto agente económico o cultural. Cuando en la vida social alguien debe indicar su trabajo remunerado -la segunda pregunta que suele hacerse, después del nombre- puede escoger privilegiar su profesión, sus funciones o su pertenencia a la universidad, generalmente en ese orden. Eso señala el grado de deseabilidad social que en nuestras latitudes tiene pertenecer a la universidad.

\section{Evaluar a los miembros de la universidad}

Si se considera, como fue de estilo en los orígenes de la universidad moderna, que su valor reside en el arte de cultivar el intelecto y no tanto en la acumulación de objetos, saberes o personas, entonces es evidente que la principal tarea del miembro activo de ella es el cultivo del intelecto en todas sus formas. Sin embargo, esta afirmación es vaga y dificulta la evaluación de los rendimientos y la calidad, toda vez que para ella se precisa disponer de productos. Tradicionalmente, se considera producto de la actividad científica la publicación en revistas especializadas, revisadas por pares e indexadas en bases de datos de fácil acceso. También, las patentes solicitadas u obtenidas, los rendimientos económicos o la adquisición de prestigio y recursos. El número e impacto de las publicaciones especializadas parecen indicadores apropiados de solvencia científica, dentro y fuera de la universidad. Pero hay productos de la actividad universitaria cuya calidad es difícil de estimar sin recurrir a la dialéctica de la oferta y la demanda. La calidad de la enseñanza, por ejemplo, es parte de un mercado no transparente, pues el producto viene a mostrar valor solamente tras muchos años y en estrecha relación con los talentos de los adquirentes de enseñanza (alumnos) o usuarios de servicios. Igualmente, las obras de creación artística enfrentan la disparidad de 
criterios debidos a la moda, el gusto y el mercado, y cuesta situarlas dentro del sistema de producciones evaluables académicamente. Por ello, la tarea de evaluar lo propiamente distintivo de la universidad es más equívoca que la tarea de evaluar, por ejemplo, las dotes de un gerente comercial. El "capital académico" es una forma particular de capital social de muy feble contextura y susceptible de valoraciones cambiantes por parte de la sociedad mayor.

La dificultad estriba en que si la institución no define con claridad su autopercepción, sus metas, sentido y misión, ponderar el trabajo de sus miembros es tarea ímproba, de consensos difíciles y resultado incierto (Kells, 1993). La universidad-empresa, definida por un carácter comercial y logro de lucro, puede en este sentido tener alguna ventaja sobre la universidad-academia, que trata con intangibles, o la universidad-mecenazgo del pueblo, que esparce los frutos y las semillas del saber y del intelecto a todos los vientos (Dittborn et al., 2004). En cierta forma, bajo los contextos populistas que de vez en cuando ganan adeptos en las economías periféricas, el compromiso político o la lealtad partidaria pueden fácilmente confundirse con solvencia intelectual y lo académico pasa a ser una forma degradada del compromiso ideológico. Ejemplos sobran en regímenes totalitarios y en democracias. Si bien no es concebible una institución de trabajo intelectual indiferente a las demandas populares, reducirla a mera satisfacción de las necesidades proletarias la condena a caducidad irreversible, como el ejemplo histórico y el simple sentido común demuestran con claridad. Al contrario de lo que afirman algunos ideólogos, el trabajo intelectual -especialmente en las ciencias- es férreamente jerarquizado y elitista. En él predomina el famoso "principio de Mateo" que describe la dinámica de la publicación científica: "A los que tienen, se les dará". Señala, simplemente, que quienes más publican tienen probabilidad de publicar aún más y multiplicar así su influencia en el campo de las ciencias. Ello queda expresado en la conocida "ley de Lotka" y en el "principio de Bradford", clásicos en la literatura científica (Lolas, 1985). En estudios empíricos sobre este asunto se los comprueba en forma reiterada, bien que con diferencias según el área específica de 
trabajo intelectual. Una forma simple de entender esta dinámica es observar que el noventa por ciento de la producción científica en un grupo determinado corre a cargo de apenas un diez por ciento de los investigadores, o incluso menos.

\section{El perfil del trabajador universitario}

Es inexacto hablar de "académicos" para referirse a docentes e investigadores universitarios. Este término debiera reservarse para los miembros de esas corporaciones llamadas "academias", a las que se asigna un papel en el cultivo desinteresado de las ciencias y las artes. Ningún docente universitario, como tampoco ningún investigador, cultiva desinteresadamente su área de trabajo. Piensa ganar su salario, adquirir reputación, ascender en prestigio social. Nada más opuesto al espíritu de las academias, en las que se supone se está no para ganar sino para entregar. Conspira además la multitud de tareas a que se aboca el universitario, desde la docencia y la administración hasta la investigación y la divulgación, que ni aun en espíritus privilegiados podría esperarse en plenitud una adecuada o razonable integración. Hoy día, las universidades que demandan una multiplicidad de papeles sociales a su personal deben reconocer que imponen exigencias desmesuradas para muchos. Buenos docentes forzados a aparentar ser investigadores de frontera. Buenos investigadores frustrados por tener que enseñar a estudiantes indiferentes. Administradores de calidad forzados a un perfil de investigadores a contrapelo. La pluralidad de funciones, tareas, obligaciones y expectativas no produce resultados uniformemente satisfactorios. Urge definir con exactitud los papeles que se exigen en esa confluencia de instituciones que es la universidad de investigación del presente (Lolas, 1998). Es probable que las "crisis" permanentes que la afectan tengan su origen en esta multiplicidad de papeles, tareas y expectativas que se asocia a sus miembros y en las demandas que la sociedad hace a estas instituciones (Searle, 2002). Sin duda alguna, una de las aporías (problemas sin solución aparente) a que se enfrenta la evaluación universitaria radica en esta indefinición de los papeles y trabajos de sus miembros, lo que a su 
vez se traduce en una incertidumbre sobre sus alcances y capacidades (Lolas, 1996).

Contribuir al debate sobre una adecuada evaluación de calidad institucional supone clarificar las tareas asociadas a las personas. En tal sentido, es esencial diferenciar los papeles sociales, llamar las cosas por su nombre y precisar metas, derechos y deberes. El panorama actual en Iberoamérica permite esperar desarrollos interesantes en el complejo proceso de tipificar, evaluar y finalmente recompensar las labores de quienes se desempeñan en la institución universitaria, considerando sus diversos tipos y sus cambiantes entornos (CINDA, 2007). Surge como sugerencia separar la contribución que cada miembro de la institución hace a sus diversas tareas y finalidades y proponer un régimen de recompensas, pecuniarias y honoríficas, que tome en cuenta esta diversidad dentro de la unidad de la institución y sus características peculiares.

\section{Referencias bibliográficas}

CINDA (2007) Educación superior en Iberoamérica. Informe 2007. Santiago de Chile: Centro Universitario de Desarrollo, CINDA.

Dittborn, Paulina; Lolas, Fernando y Salazar, José Miguel (2004) El mercado y la educación superior. Calidad en la Educación, 20, pp. 197-209.

Kells, H. Richard (1993) Autorregulación en la Educación Superior Chilena. Santiago de Chile: Consejo Superior de Educación.

Heidegger, Martin (1958) La época de la imagen del mundo. Santiago de Chile: Edición Anales de la Universidad de Chile.

Instituto de Filosofía, Facultad de Humanidades y Ciencias, Universidad de Montevideo (1958) La idea de la universidad en Alemania. Buenos Aires: Editorial Sudamericana.

Lolas, Fernando (1985) Sobre cientificidad. En Notas al Margen. Ensayos. Santiago de Chile: Editorial Cuatro Vientos.

Lolas, Fernando (1996) Algunas aporías de la institución universitaria en Chile. En Riveros, Luis \& Sapag, Nassir (editores) Retos y dilemas de la gestión universitaria. Santiago de Chile: Facultad de Ciencias Económicas y Administrativas-CIADE, 1996. 
Lolas, Fernando (1998) Sobre el trabajo universitario: una nota personal. En Fuller, Amanda (editora) Huella y Presencia, tomo II. Santiago de Chile: Universidad de Chile, Facultad de Medicina.

Lolas, Fernando (2004) La educación superior chilena en tiempos de decisión. Anales del Instituto de Chile, Vol. XXIV, No 2, pp. 69-81.

Mellafe, Rolando; Rebolledo, Antonia y Cárdenas, Mario (1992) Historia de la Universidad de Chile. Santiago de Chile: Universidad de Chile, Ediciones de la Biblioteca Central.

Serrano, Sol (1993) Universidad y nación. Chile en el siglo XIX. Santiago de Chile: Editorial Universitaria.

Searle, John (2002) La universidad desafiada. Santiago de Chile: Universidad Central de Chile y CPU. Bravo y Allende.

Recibido: 24 de abril de 2008

Aceptado: 12 de mayo de 2008 